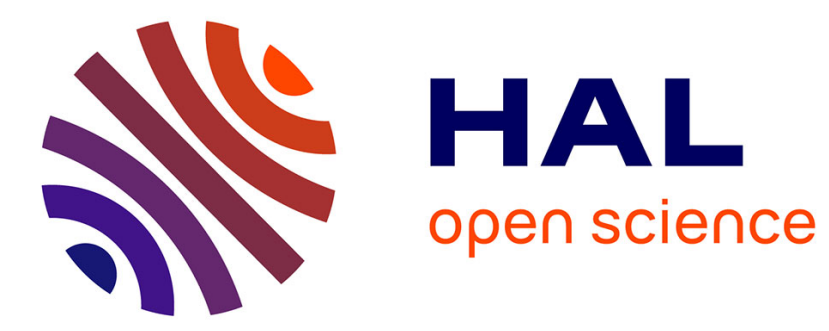

\title{
Electrical and elastoresistance properties of evaporated thin films of bismuth
}

M. Saleh, J. Buxo, G. Dorville, Gérard Sarrabayrouse

\section{To cite this version:}

M. Saleh, J. Buxo, G. Dorville, Gérard Sarrabayrouse. Electrical and elastoresistance properties of evaporated thin films of bismuth. Revue de Physique Appliquée, 1979, 14 (2), pp.405-413. 10.1051/rphysap:01979001402040500 . jpa-00244609

\section{HAL Id: jpa-00244609 https://hal.science/jpa-00244609}

Submitted on 1 Jan 1979

HAL is a multi-disciplinary open access archive for the deposit and dissemination of scientific research documents, whether they are published or not. The documents may come from teaching and research institutions in France or abroad, or from public or private research centers.
L'archive ouverte pluridisciplinaire HAL, est destinée au dépôt et à la diffusion de documents scientifiques de niveau recherche, publiés ou non, émanant des établissements d'enseignement et de recherche français ou étrangers, des laboratoires publics ou privés. 


\title{
Electrical and elastoresistance properties of evaporated thin films of bismuth
}

\author{
M. Saleh, J. Buxo, G. Dorville (*) and G. Sarrabayrouse \\ Laboratoire d'Automatique et d'Analyse des Systèmes du C.N.R.S. \\ 7, avenue du Colonel-Roche, 31400 Toulouse, France.
}

(Reçu le 21 février 1978, révisé le 11 octobre 1978, accepté le 23 octobre 1978)

\begin{abstract}
Résumé. - Les résultats montrent que la couche de résine utilisée pour rendre les couches de bismuth utilisables en tant que jauges de contrainte n'apporte aucune modification majeure des propriétés électriques du bismuth si on les compare à celles des couches de bismuth déposées sur d'autres types de substrats. L'article discute les propriétés électriques des couches obtenues, selon trois processus d'élaboration, en fonction de la taille des microcristallites, de leur texture, et du libre parcours moyen des porteurs. Un développement théorique permet de rendre compte de l'ordre de grandeur et de la dépendance thermique de la modulation sous contrainte de la conductibilité $(\delta \sigma / \sigma)$. La déformation transversale des couches fait apparaître des facteurs de jauge systématiquement plus élevés que ceux des jauges longitudinales. Il apparaît que cet effet doit être relié à la modulation par la contrainte de la taille du grain.
\end{abstract}

\begin{abstract}
The results obtained show that the resin layer substrate which is convenient for the bismuth layer to be used as a practical strain gauge device, does not bring about any major modification in the bismuth electrical properties when compared to those of bismuths layers deposited onto other substrates. The difference between the conduction properties of three differently processed films are discussed in terms of the grain size, of the textures and of the carrier mean free path. A theory has been developed which gives the order of magnitude and the temperature dependence of the conductivity modulation under strain $(\delta \sigma / \sigma)$. The transversally stressed films show systematically gauge factor values larger than those of the longitudinally stressed one $\mathrm{s}$. This effect appears to be linked to the modulation of the grain size under stress.
\end{abstract}

1. Introduction. - Many works have been published on electrical properties and structural investigation of bismuth films [1-7]. In experiments with bismuth films reported so far, these films have been generally prepared by evaporation onto glass or mica substrates and it has been shown that these films consist of small crystallites with the trigonal axis perpendicular to the plane of the film. In the present work, the bismuth films used were deposited onto a metallic plate isolated from the active bismuth film by a resin layer, which is deposited by the electrophoresis technique on the metallic plate. Their structural investigation by X-ray diffraction, electronic diffraction and scanning electron microscope showed that highly textured films were also obtained in this case.

Measurements of the conductivity and Hall constant values have also been made over temperatures ranging from 77 to $300 \mathrm{~K}$. Moreover, the effect of some preparation conditions, namely, hot substrate

(*) Société Jules Richard, 116, quai de Bezons, 95 Argenteuil, France.

REVUE DE PHYSIQUe APPLIQUÉE. - - T. 14, No 2, FÉVRIER 1979 and annealing after evaporation, on the transport properties and the structure of the films is presented.

The gauge factor $K$ of these films has been measured and found to be fairly high, in agreement with other published work [8]. The stress was applied transversally and longitudinally to the direction of the current flow, and values of the gauge factor corresponding to a transversally stressed film $\left(K_{\mathrm{T}}\right)$ were found to be systematically higher than those $\left(K_{\mathrm{L}}\right)$ measured for the longitudinal stress. Furthermore, the ratio $\left(K_{\mathrm{T}} / K_{\mathrm{L}}\right)$ was found to be approximately one order of magnitude higher than predicted from purely geometric and mechanical effects. Thus, the conductivity modulation $(\delta \sigma / \sigma)_{\mathrm{T}}$ is greater than $(\delta \sigma / \sigma)_{\mathrm{L}}$, indicating additional physical effects on the variation of conductivity with the direction of the stress. Both $K_{\mathrm{T}}$ and $K_{\mathrm{L}}$ have been measured for temperatures ranging from 120 to $300 \mathrm{~K}$.

The effect of thermal treatments on the conductivity values has been reported to be caused by an increase of the crystallite dimensions. The same effect has been obtained for the resin deposited layers studied here. According to the model proposed by Mayadas et al. [9] for polycrystalline films and reported by Le Traon [4], 
the temperature coefficient of the resistance is controlled by the ratio of the crystallite dimensions to the mean free path within the crystallite. This effect also plays an important role in controlling the behaviour of the coefficient of our samples. The sign of the Hall constant has provided the type of carriers which predominates. It has appeared that the type of carrier involved in the conduction mechanism is particularly influenced by the thermal treatment and may depend upon temperature. Also Hall effect constant measurements will provide some information on the texture quality and its relation with the film thickness and the thermal treatment.

For the elastoresistance properties, a theory has been developed and appears to account for both the order of magnitude of $(\delta \sigma / \sigma)$ and its temperature dependence in terms of modulating the occupancy of bismuth conduction band under strain. When the model suggested by Mayadas et al. [9] is used to compute the conductivity modulation under strain, it appears that the expression of $(\delta \sigma / \sigma)$ includes a term connected with the grain size modulation. This grain size modulation will thus oppose to the term $(\delta n / n)$ in the case of longitudinal effect, whereas the two terms add up in the case of the transversal one.

2. The experimental devices. - The experimental devices are made up of a metallic substrate isolated from the active bismuth film by a resin layer. The details of fabrication are described below.

2.1 The SUBSTRATES. - Aluminium substrates of dimensions $35 \times 15 \times 1 \mathrm{~mm}$ were used for conductance and Hall measurements. For the elastoresistance study the substrate was a triangular steel plate of thickness $e=0.6 \mathrm{~mm}$, length $L=60 \mathrm{~mm}$, and base $b=20 \mathrm{~mm}$ (Fig. 1). The shape of the substrate is such that its mechanical behaviour under strain is

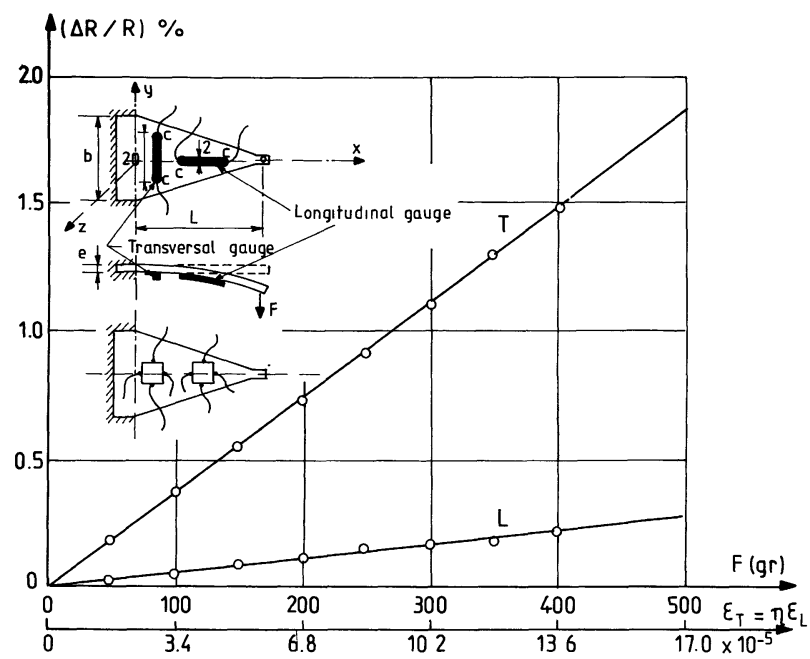

Fig. 1. $-a$ ) Triangular steel plate with vacuum deposited transversal and longitudinal bismuth films. C : electrical contacts (figures in millimeters). $b$ ) The relation between the variation of the film resistance and the strain at room temperature. Thickness $=2000 \AA$, process 3 . T, L corresponds to transversal and longitudinal stress respectively. c) Substrate with two square layers of bismuth films of thickness $500 \AA$, process 2 .

isostatic [10], i.e. the strain value in the direction of the $x$-axis

$\varepsilon_{\mathrm{L}}=\frac{\delta L}{L}$

is unique for any point on the surface of the triangle and is given by $[10]$ :

$\varepsilon_{\mathrm{L}}=\frac{6 F L}{E e b^{2}}$

where $F$ is the force applied at the apex of the triangle and $E$ is the Young's modulus of the plate material. The triangular plate is clamped at its base (i.e. as a cantilever) and the rest of it deforms under the action of $F$. The values used for $F$, the bending force, range between 0 and $500 \mathrm{~g}$.

Accordingly the strain value in the direction of the $y$-axis :

$\varepsilon_{\mathrm{T}}=\frac{\delta b}{b}$

is given by

$\varepsilon_{\mathrm{T}}=\varepsilon_{\mathrm{L}} \cdot \eta$

where $\eta$ is the Poisson's ratio; for steel $\eta \simeq 0.3$ [10].

2.2 The INTERMEdiate INSUlating LAYER. - A $10 \mu \mathrm{m}$ thick resin layer was deposited on the metallic plate using the method of auto-regulated electrophoresis $[11,12]$ which appeared to provide a uniform insulating layer. A thickness of $10 \mu \mathrm{m}$ was found to be sufficient to obtain both enough insulation and good adherence.

2.3 The BISMUTH FILMS. - Bismuth films of different thicknesses were deposited onto the resin layer by thermal evaporation under vacuum of $10^{-6}$ torr, at a rate of evaporation of $50 \AA / \mathrm{s}$. The thickness of the film is controlled through the available amount of bismuth, which was placed either on a tungsten wire or in a molybdenum crucible, which were heated electrically. A linear dependence between the quantity

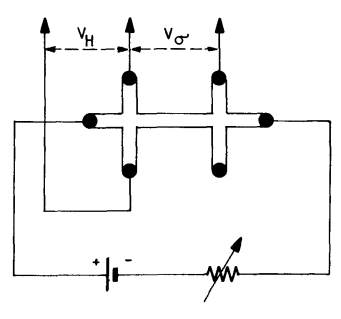

a) four contact measurement

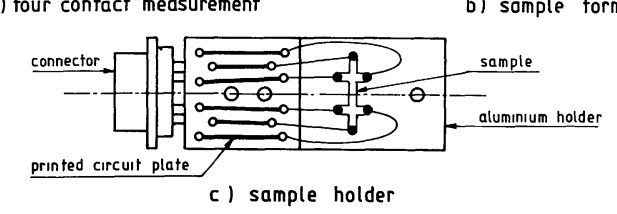

Fig. 2. - a) Electrical measurements scheme. b) Samples form (figures in millimeters). c) Sample holder. 
of bismuth versus the film thicknesses, as measured by a Taylor Hobson Talystep instrument, has been found and amounts to be of $20 \AA$ per milligram of bismuth. For the conductance and Hall effect measurements, $\mathrm{Bi}$ deposition was in the geometry shown on figure 2, and for elastoresistance studies in the one shown on figure 1 , where the alignment of the deposited films makes it possible to study both its longitudinal and transversal properties. Thick bismuth films were used for the contacts in order to eliminate the diffusion process which may occur if another metal is used [4]. Leads were attached to the thick Bi films by using silver paint.

Three differently processed films, detailed in table I, have been studied.

\section{TABLE I}

$\begin{array}{ccc}\text { Process } \mathrm{n}^{\circ} & \begin{array}{c}\text { Substrate } \\ \text { temperature }\end{array} & \text { Post-evaporation treatment } \\ - & - & - \\ 1 & \text { room temperature } & \text { none } \\ 2 & \text { room temperature } & 240^{\circ} \mathrm{C} \text {, for } 45 \text { min., in vacuum }\left(^{*}\right) \\ 3 & 220^{\circ} \mathrm{C} & 240^{\circ} \mathrm{C} \text {, for } 45 \text { min., in vacuum }\end{array}$

$\left.{ }^{*}\right)$ It has been found experimentally that this parameters provide the best stability of the resistance value with time [13].

3. Structural investigation of thin bismuth films. Different methods have been used to prepare evaporated bismuth films, some of them are listed on table II. $\mathrm{X}$-ray diffraction and scanning electron microscope are among the techniques used for observing the corresponding structure. The conclusion of these examinations is that the deposited films are textured and made up of crystallites with a common trigonal axis [III] perpendicular to the substrate plane [1-3, 5]. For the films used in the present study, an X-ray diffraction investigation has first been carried out. The diffraction patterns were obtained by means of the Debye-Scherrer method. A kristalloflex 4 Siemens diffractometer was used and the samples were placed in the holder of a goniometer in the Bragg Brentant parafocusing system. A proportional counter scanned the diffraction peaks at a rate of $30 \mathrm{~min} / 20$ degrees. A cobalt target tube and a back monochromator were used throughout the investigation. The results recorded simultaneously on an $\mathrm{X}-\mathrm{Y}$ chart are shown on figure 3. Table III shows the measured intensities (I) for each diffraction pattern, relative to the intensity of the strongest line (111) taken as a reference $I_{\text {ref }}=100$ together with the values of the inter-planar spacing $d_{h k l}$. Lines other than (111) and (222) were not shown by the diffraction pattern.
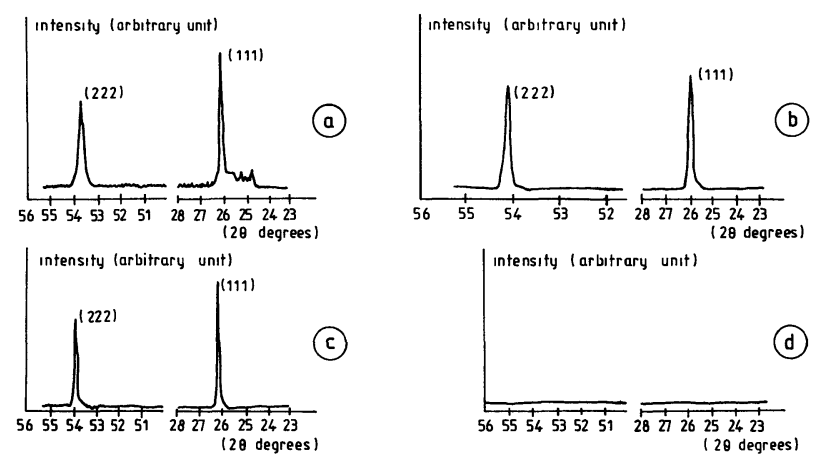

Fig. 3. - The intensity of diffracted X-ray for $2 \theta$-angles. a) $\mathrm{Bi}$ layer $1000 \mathrm{~A}$ thick, preparation process 1 . b) Bi layer $2500 \AA$ thick, preparation process 2. c) Bi layer $3000 \AA$ thick, preparation process 3. d) Virgin resin.

The X-ray structural analysis of the samples has therefore shown that the films are highly textured and the textures of the polycrystals are rhombohedric with (111), (222) pseudo f.c.c. Miller indices.

Where (1), (2) and (3) represent the preparation process number as presented on table $I$.

Scanning electron microscope observations, figure 4, were also made and showed the presence of microcrystallites. These crystallites in the films are thus oriented with trigonal axis perpendicular to the film surface as observed earlier [5].

Table II

\begin{tabular}{lcc}
\multicolumn{1}{c}{ References } & $\begin{array}{c}\text { Substrate } \\
\text { type }\end{array}$ & $\begin{array}{c}\text { Evaporation } \\
\text { rate }\end{array}$ \\
Hoffman et al. $[1]$ & - & - \\
Duggal et al. $[2]$ & mica & $10-100 \AA / \mathrm{min}$. \\
Le Traon et al. $[3]$ & mica & $400-600 \AA / \mathrm{min}$. \\
Garcia et al. $[5]$ & glass & $50-100 \AA / \mathrm{s}$ \\
& mica & $60 \AA / \mathrm{min}$.
\end{tabular}

Post-evaporation
treatment
$155-\overline{165}{ }^{\circ} \mathrm{C}$
$100-\overline{150}{ }^{\circ} \mathrm{C}$

Table III

\begin{tabular}{crcc}
\multicolumn{5}{c}{ Layer 1} & $000 \AA(1)$ \\
$I$ & $I_{\text {ref }}$ & $d(\AA)$ & $h k l$ \\
- & - & - & - \\
9.7 & 100 & 3.96 & 111 \\
6.1 & 63 & 1.98 & 222
\end{tabular}

\begin{tabular}{|c|c|c|}
\hline \multicolumn{3}{|c|}{ Layer $2500 \AA$ (2) } \\
\hline$I_{\text {ref }}$ & $d(\AA)$ & $h k l$ \\
\hline & - & - \\
\hline 100 & 3.96 & 111 \\
\hline 81 & 1.98 & 222 \\
\hline
\end{tabular}

\begin{tabular}{cccc}
\multicolumn{4}{c}{ Layer $3000 \AA(3)$} \\
$I$ & $I_{\text {ref }}$ & $d(\AA)$ & $h k l$ \\
- & - & - & - \\
9.5 & 100 & 3.96 & 111 \\
6.7 & 70 & 1.98 & 222
\end{tabular}

Bi Cryst. ASTM [14]
$\begin{array}{ccc}I & d(\AA) & h k l \\ - & - & - \\ 9 & 3.95 & 111 \\ 3 & 1.98 & 222\end{array}$



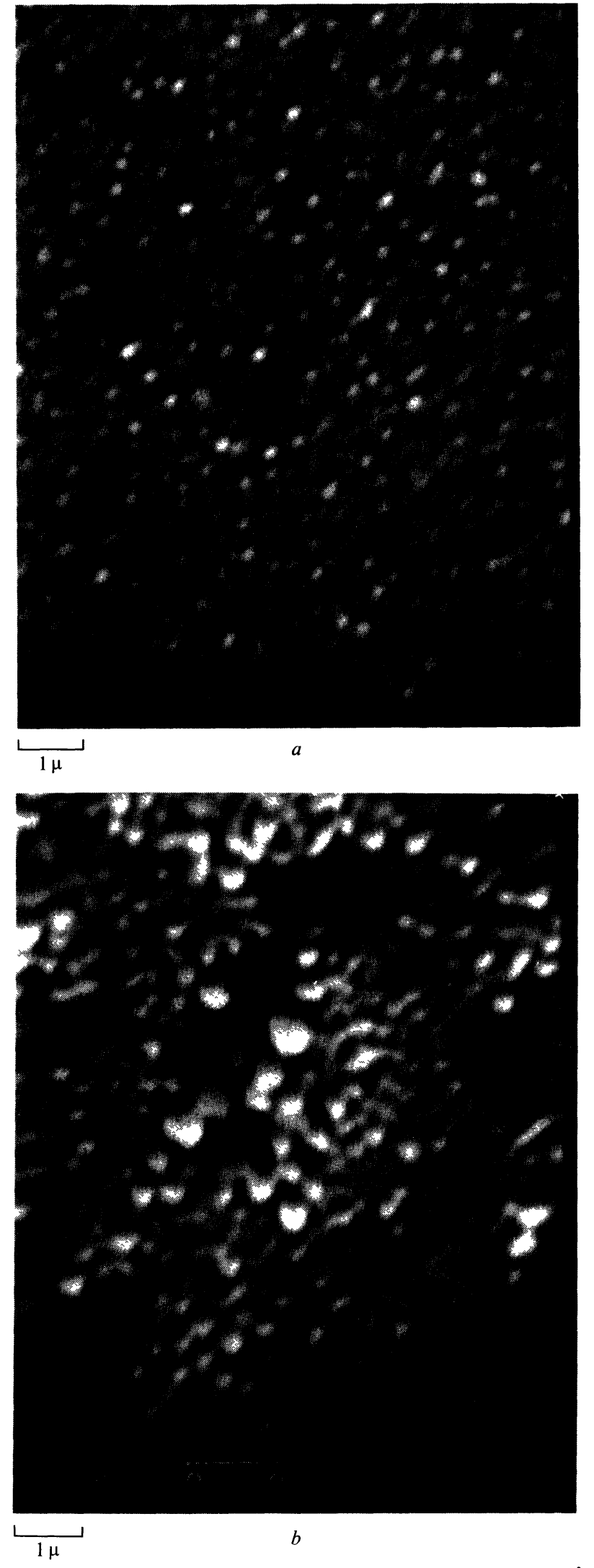

Fig. 4. - Scanning electron micrographs for Bi films. a) $200 \AA$ thick, preparation process $1 . b) 2000 \AA$ thick, preparation process 3 .

To complete the structural investigation, a study was also made of the electronic diffraction pattern by reflection. Figure 5 shows the observed pattern

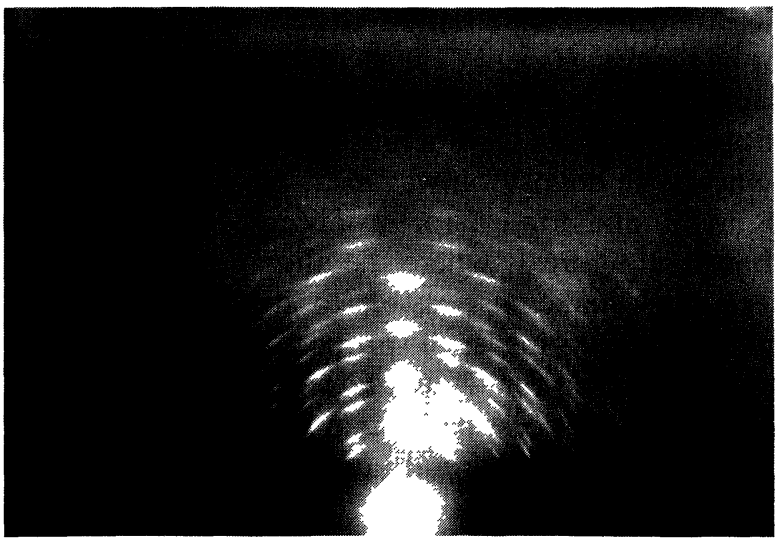

Fig. 5. - Diagram of electronic diffraction for Bi films $1500 \AA$ thick, substrate temperature $130^{\circ} \mathrm{C}$, annealing $240^{\circ} \mathrm{C}, 45 \mathrm{~min}$., in vacuum.

which confirms the existence of crystallites with trigonal common axis.

4. Electrical properties of thin bismuth films. In this section the influence of the preparation conditions on the electrical properties of the films is presented. The results are compared to those of other authors.

Figure 6 shows the variation of the conductivity with temperature for various thicknesses and for processes 1,2 and 3 .

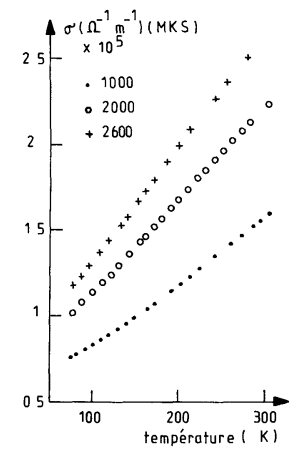

(a)

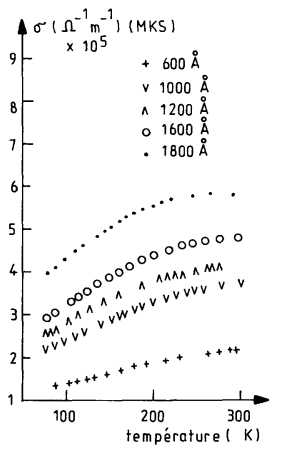

(b)

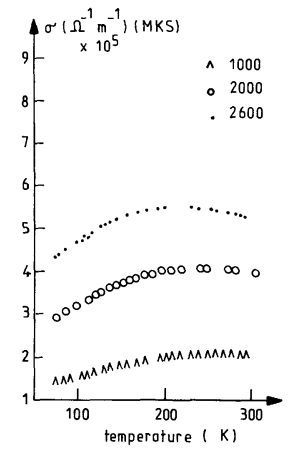

(c)
Fig. 6. - Conductivity versus temperature for various thicknesses of Bi films (process 1, 2 and 3).

The influence of the condensation rate on the values of the conductivity was measured and discussed by Le Traon [4] who obtained $2.5 \times 10^{5} \mathrm{ohm}^{-1} \mathrm{~m}^{-1}$ (MKS) for Bi films of thicknesses greater than $3000 \AA$ evaporated onto glass substrates at room temperature and for a condensation rate of $50 \AA / \mathrm{s}$. The corresponding values for films prepared according to process 1 and deposited at the same condensation rate have been found to be $2.7 \times 10^{5} \mathrm{ohm}^{-1} \mathrm{~m}^{-1}$ (MKS).

The influence of the post-deposition thermal treatment has been measured (Fig. 6b,c). It has been reported [4] that such a treatment gives rise to a hysteresis effect when performed on glass deposited 
films at room temperature, Le Traon has measured this effect in terms of :

$\zeta=\frac{R_{0}-R_{\mathrm{T}}}{R_{0}}$

where $R_{\mathrm{T}}$ and $R_{0}$ respectively, stand for the resistance value after and before thermal treatment at $T$ oC. Table $\mathrm{V}$ compares the present results to those in [4].

\section{Table V}

$$
\begin{array}{ccccc}
\multicolumn{2}{c}{\text { Film thickness en } \AA} & 1200 & 2500 & \sim 3000 \\
\zeta=\frac{R_{0}-R_{\mathrm{T}}}{R_{0}} \% & \text { Present work } & 70 & 42 & 38 \\
& \text { Ref. [4] } & 45 & - & 20
\end{array}
$$

The influence on the conductivity of the substrate temperature during evaporation has been measured figure $6 c$. Komnik et al. [15] showed that for substrates at temperatures greater than $90^{\circ} \mathrm{C}$, bismuth films are condensed in the form of small spherical drops. David et al. [16] confirmed this property by direct analysis in the interior of a diffratograph for bismuth films deposited onto amorphous collodion, where at $80^{\circ} \mathrm{C}$ the bismuth film appears as a crystal and at $90{ }^{\circ} \mathrm{C}$ as a liquid. The recrystallisation of the bismuth occurs via liquid $\rightarrow$ solid transformation. Although the recrystallisation does not seems to have any significant effect on the texture of bismuth films deposited on resin layer, as shown by the X-ray analysis, its effect on the value of conductivity is not large. The main feature of the curves on figure $6 b, c$ is that the conductivity passes through a maximum value at higher temperatures.

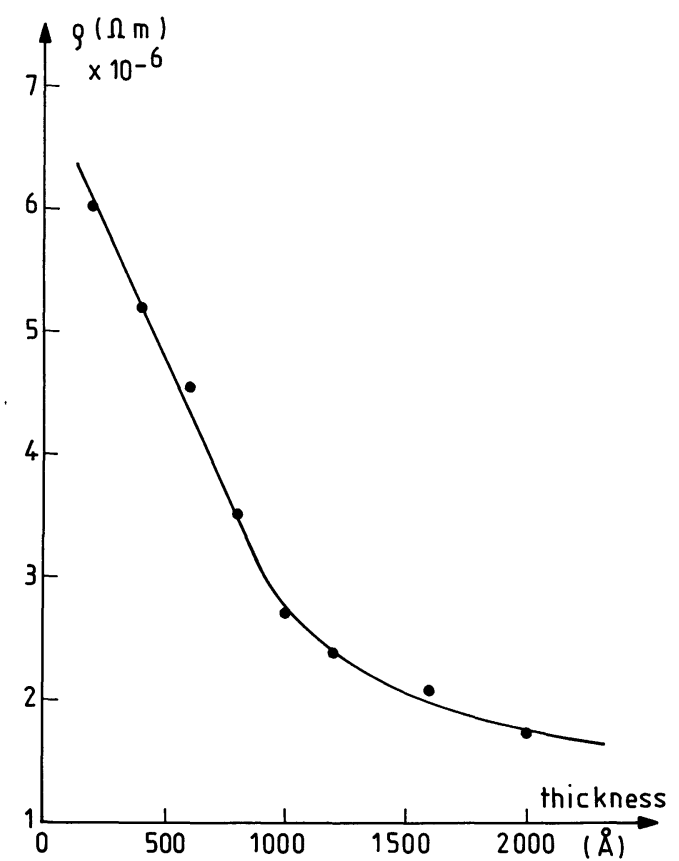

Fig. 7. - Resistivity variation with film thickness at room temperature (process 2).
In order to study the effect of film thickness on the continuity of the bismuth surface, the resistivity measurements have been extended to thicknesses as low as $200 \AA$. Figure 7 shows the variation of the film resistivity with thickness. The variation of the curve slope is not sharp enough as to suggest some discontinuity in the film surface. This also seems to have been confirmed by electron micrograph observations on $200 \AA$ thick films [16].

The temperature coefficient of the resistance of $\mathrm{Bi}$ films for different preparation conditions is shown in figure 8. It appears that the curves for films including thermal treatments (processes, 2 and 3) are shifted towards lower temperatures. Moreover, the temperature coefficient of the resistance can change its sign for films prepared according to process 3 .

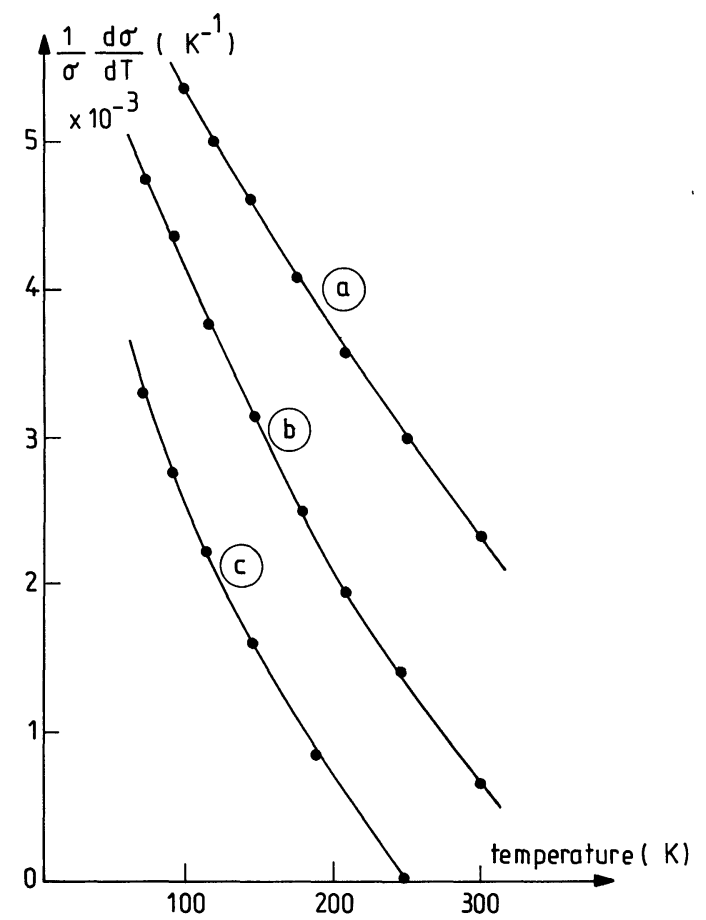

Fig. 8. - Temperature coefficient of the resistance versus temperature. Curves $a, b$ and $c$ correspond to preparation process 1,2 and 3 respectively.

Figure 9 shows the variation of the Hall constant value with temperature for different film thicknesses. For process $n^{0} 1$, it appears that for $T<200 \mathrm{~K}$, the value of $R_{\mathrm{H}}$ is negative while for $\mathrm{Bi}$ films including thermal treatments $R_{\mathrm{H}}$ is positive all over the temperature range of the measurements.

The mobility value is calculated from the experimental values of the Hall constant $R_{\mathrm{H}}$ and from the conductivity $\sigma$ according to $: \frac{1}{\mu}=\frac{1 / R_{\mathrm{H}}}{\sigma}$. The variation of the mobility with temperature for various film thicknesses is shown on figure 10 for the different preparation conditions. It is generally observed that the mobility values for process 1 films are the smallest. Moreover, it can be seen from figure 10 that, for these 


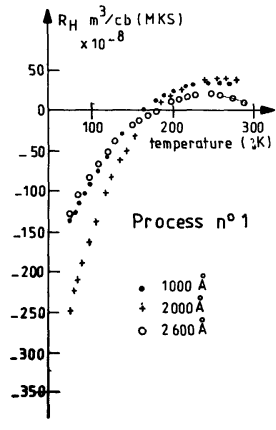

(a)

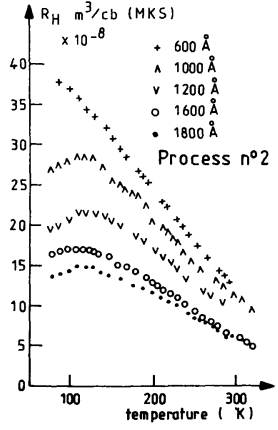

(b)

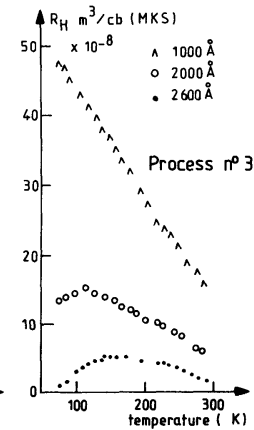

(c)
Fig. 9. - Variation of the Hall constant versus temperature for various film thicknesses (process 1, 2 and 3).

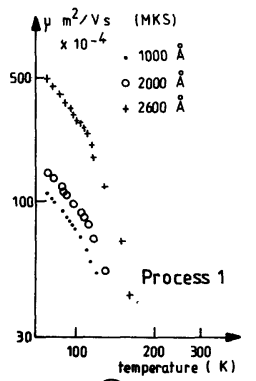

(a)

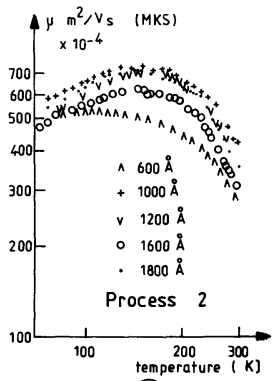

(b)

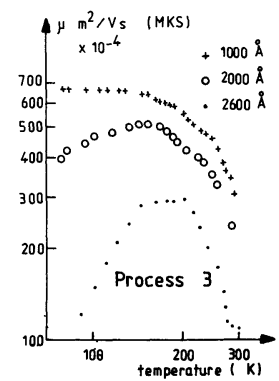

(c)
Fig. 10. - Variation of the mobility versus temperature for various film thicknesses (process 1, 2 and 3).

films, when the temperature decreases $(<100 \mathrm{~K})$, the mobility of electrons (which corresponds to the negative value of $R_{\mathrm{H}}$ ) dominates and follows a $T^{-\alpha}$ law, where $\alpha \sim 1.4$. For higher temperatures the mobility of holes (which corresponds to positive values of $R_{\mathrm{H}}$ dominates). For films corresponding to process 2 , the variation of the mobility with temperature also follows a $T^{-\alpha}$ law, where $\alpha \sim 1.8$ but only within the range $200-300 \mathrm{~K}$.

5. Electrical measurements under strain. - Measurements have been made to evaluate both the longitudinal and the transversal gauge factors for different bismuth film thicknesses, at different temperatures and for different deformation forces. A linear relationship links the strain value $\varepsilon$ to $\Delta R / R$ as shown on figure 1 . This linear behaviour has already been reported $[17,18]$ and shows that the adherence properties of the films deposited upon resin are as convenient as those in the preceding studies [17, 18]. The slope of each of the two straight lines given on figure 1 provides the values of $K_{\mathrm{L}}$ and $K_{\mathrm{T}}$ i.e., the longitudinal and transversal gauge factor, defined by

$K_{\mathrm{L}}=\left(\frac{\Delta R}{R}\right)_{\mathrm{L}} / \varepsilon_{\mathrm{L}}$ and $K_{\mathrm{T}}=\left(\frac{\Delta R}{R}\right)_{\mathrm{T}} / \varepsilon_{\mathrm{T}}$.

Figures 11 and 12 show the effect of temperature on $\left(\frac{\Delta R}{R}\right)_{\mathrm{L}}$ and $\left(\frac{\Delta R}{R}\right)_{\mathrm{T}}$ and the relationship

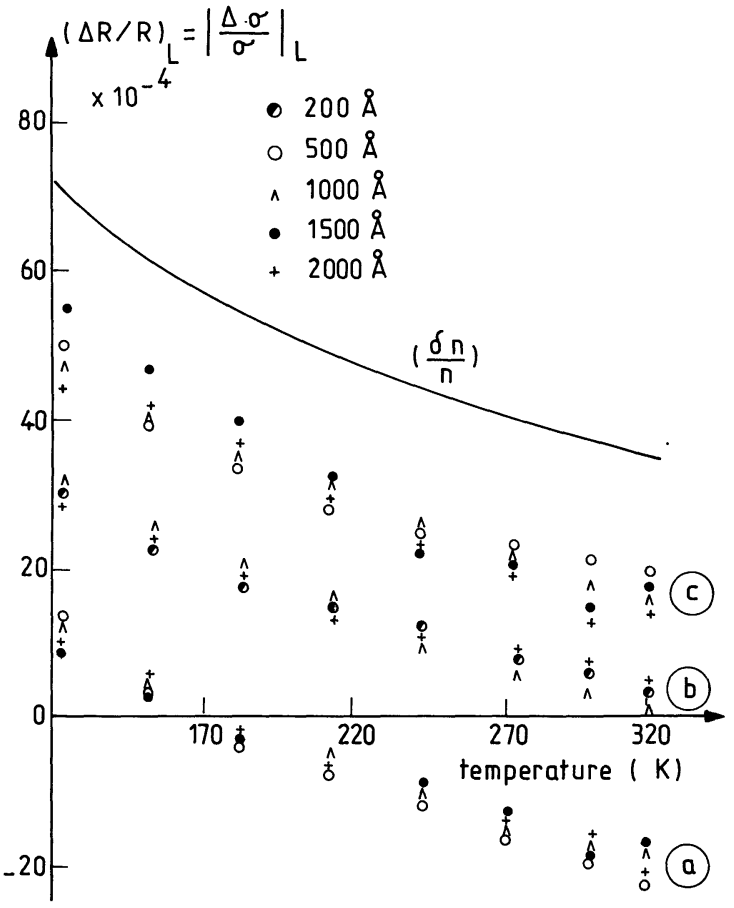

Fig. 11. - Variation of the longitudinal $(\Delta R / R)$ value with temperature. $F=200 \mathrm{~g}$ (process 1,2 and 3 ), also $\delta n / n$ curve is shown on figure.
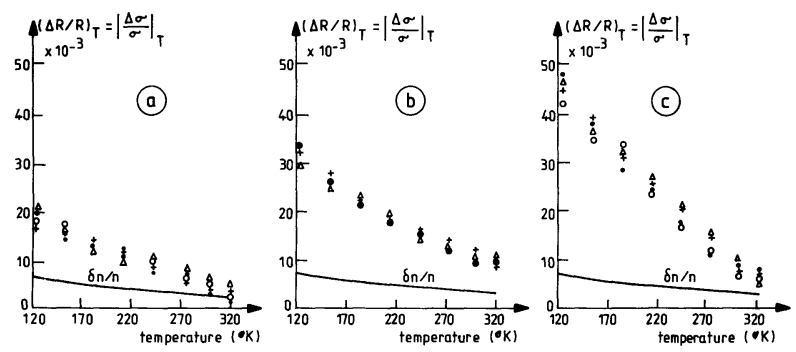

$2000 \AA \quad .1500 \AA$

$$
\wedge 1000 \AA \circ 500 \AA \quad 200 \AA
$$

Fig. 12. - Variation of the transversal $(\Delta R / R)$ value with temperature, for different thicknesses. $F=200 \mathrm{~g}$ (process 1,2 and 3)

$$
\left(\frac{\Delta R}{R}\right)_{\mathrm{T}}|>|\left(\frac{\Delta R}{R}\right)_{\mathrm{L}} \mid
$$

appears to be maintained over the whole temperature range of the measurements. In order to avoid hysteresis effects, the measurement range is restricted to temperatures lower than $60{ }^{\circ} \mathrm{C}$.

In order to show clearly that the systematic difference between the values of $K_{\mathrm{T}}$ and $K_{\mathrm{L}}$ is not merely caused by some geometrical effects, the experiment has also been carried out on two bismuth films deposited through a square mask $10 \times 10 \mathrm{~mm}$ and situated on the substrate plate in the position of the preceding rectangular films as shown on figure 1 . The gauge factor values were found to be $K_{\mathrm{T}}=139$ and $K_{\mathrm{L}}=20$ at room temperatures and identical for both films.

It has been found that for the three processing techniques and within the temperature range of measu- 
rement, the values of $K_{\mathrm{T}}$ is always positive. Also the values of $K_{\mathrm{L}}$ are positive for the two processes 2 and 3, whereas for process $1, K_{\mathrm{L}}$ although positive at low temperatures attains negative values for high temperatures $(>170 \mathrm{~K})$.

6. The relaxation effect. - It has been found in agreement with Le Contellec et al. [8] and Kuwahara et al. [19] that the values of $K_{\mathrm{L}}$ and $K_{\mathrm{T}}$ are time dependent. The measured values described above correspond to the relaxed gauge factors, i.e. the values of the resistance are measured once the relaxation is completed. The relaxation coefficient $\varnothing=\frac{\Delta R x}{R}$ as defined in figure 13 , is found to be positive (negative) for the compressed (tensile) longitudinal bismuth films and negative (positive) for the compressed (tensile) transversal films, as shown in figure 13. This property has also been found in the case of aluminium films [19].
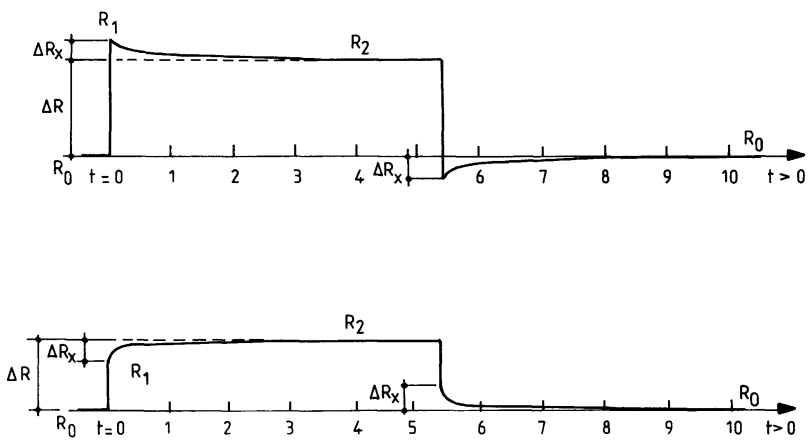

Fig. 13. - Relaxation curves for process 1 at room temperature. $F=100 \mathrm{~g}$ (compressed). Typically obtained values are : Transversal : $R_{0}=733 \Omega, R_{1}=739.99 \Omega, R_{2}=738.88 \Omega$,

$\varnothing=R_{2}-R_{1} / R_{2}-R_{0}=-0.187$.

Longitudinal $: R_{0}=923 \Omega, R_{1}=926.16 \Omega, R_{2}=927 \Omega$,

$\varnothing=R_{2}-R_{1} / R_{2}-R_{0}=+0.21$.

time in minutes.

7. Discussion of the results. - The work of Neuman et al. [20], Garcia et al. [5] and Le Traon [4] showed that an increase of the film thicknesses brings about an increase of the crystallite size which in turn causes larger values of the conductivity value. According to Neuman [21] the relation between the conductivity and the mean crystallite size $\overline{d_{\mathrm{g}}}$ can be expressed by :

$\sigma=\frac{\sqrt{2}}{\pi} \frac{n e^{2}}{\sqrt{\left(E_{\mathrm{F}}-E_{\mathrm{c}}\right) m_{\mathrm{e}}}} \overline{d_{\mathrm{g}}}$

where $n$ is the electron concentration, $m_{\mathrm{e}}$ the effective mass and $E_{\mathrm{F}}$ is the Fermi level. $E_{\mathrm{c}}$ is defined in figure 14.

Also the higher valvue of the conductivity for films followed by a thermal treatment, as shown on figure 6 , has been reported to be caused by an increase of the crystallite dimensions. The preceding experimental values figure 6 show for $\overline{d_{\mathrm{g}}}$ an increase of $125 \%$ for

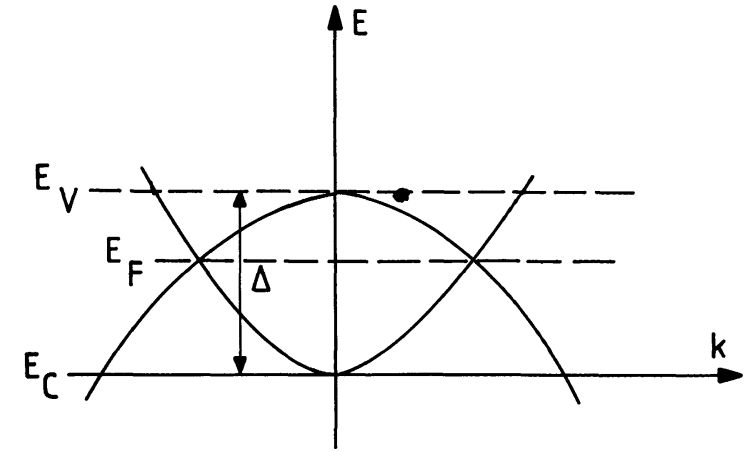

Fig. 14. - Band structure of bulk bismuth.

process 2 and of $25 \%$ for process 3 , with respect to the value of $\overline{d_{\mathrm{g}}}$ in process 1 .

Nevertheless, expression (5) cannot account for the behaviour of the temperature coefficient of the resistance. As pointed out by Le Traon [4] a theoretical model put forward by Mayadas et al. [9] where $\sigma$ is not only a function of $d_{\mathrm{g}}$ but also of the mean free path $l_{0}$ provides the experimental features of $\frac{1}{\sigma} \frac{\mathrm{d} \sigma}{\mathrm{d} T}$. Indeed, in the framework of this model the temperature coefficient of the resistance is given by :

$$
\begin{aligned}
\frac{1}{\sigma_{\mathrm{g}}} \frac{\mathrm{d} \sigma_{\mathrm{g}}}{\mathrm{d} T} & =\frac{1}{\sigma_{0} \mid l_{0}} \frac{\mathrm{d}}{\mathrm{d} T}\left[\sigma_{0} \mid l_{0}\right]+\frac{1}{5} \frac{d_{\mathrm{g}}}{l_{0}} \frac{1-R}{R} \frac{\mathrm{d} l_{0}}{\mathrm{~d} T} \times \\
& \times \frac{1}{\frac{1}{4}-\frac{1}{5} \frac{d_{\mathrm{g}}}{l_{0}} \frac{1-R}{R}}
\end{aligned}
$$

where $\sigma_{\mathrm{g}}$ is the conductivity in the presence of both grain boundaries and background scattering, $\sigma_{0}$ the conductivity in the absence of grain boundaries, $R$ the reflection coefficient.

The first term on the right hand side of equation (6) is proportional to $\frac{1}{n} \frac{\mathrm{d} n}{\mathrm{~d} T}$, whereas the second term is proportional to $d_{\mathrm{g}} / l_{0}$. Furthermore, $\mathrm{d} n / \mathrm{d} T$ is positive, while $\mathrm{d} l_{0} / \mathrm{d} T$ is negative. The temperature coefficient of the resistance is then dependent on the thermal treatment via the ratio $d_{\mathrm{g}} / l_{0}$ which may cause the sign of $\frac{1}{\sigma_{\mathrm{g}}} \frac{\mathrm{d} \sigma_{\mathrm{g}}}{\mathrm{d} T}$ to change at high temperature. As a consequence the thermal treatment in process 2 and 3 does not only bring about an increase in the grain size but is also likely to modify the mean free path value $l_{0}$. Indeed, the maximum in the curve $\sigma(T)$ is progressively shifted towards lower temperatures when proceeding from process 2 to process 3 . The conductivity values for process 2 being fairly higher than those on process 3 , it should be concluded that the values of $l_{0}$ involved in process 3 are smaller than those in process 2.

The Hall constant measurements will provide some information on the one hand, on the relation between film thickness and texture, and on the other hand on 
the correlation, if any, between the thermal treatment and the texture quality.

According to the theoretical approach made by Abeles and Meiboom [22] including the anisotropy of bismuth, $R_{\mathbf{H}}$ is made up of two components, namely $R_{\|}$when the applied magnetic field is parallel to the trigonal axis of the cristallite and $R_{\perp}$ when it is perpendicular to this axis. $R_{\|}$being positive, $R_{\perp}$ negative and $\left|R_{\perp}\right| \gg\left|R_{\|}\right|$.

For microcrystallites with trigonal axis parallel to the magnetic field $R_{\mathrm{H}} \sim R_{\|}$and the measured $R_{\mathrm{H}}$ values can be described by [3] :

$R_{\mathrm{H}}=\alpha R_{\perp}+\beta R_{\|}$

where $\alpha$ and $\beta$ have been assumed to be independent from temperature.

Figure $9 b, c$ then indicate that the smaller the film thickness, the greater the value of $R_{\mathrm{H}}$ (positive) and hence the better the texture quality. Similar experimental results were obtained by Salardenne [23] on glass deposited films. The author's interpretation of the results is also very similar.

The variation of the sign of $R_{\mathrm{H}}$ with temperature observed for Bi films evaporated according to process 1 and shown on figure $9 a$ can also be discussed by considering the ratio $R_{\perp} / R_{\|}$[3] in connection with the temperature dependence of the mobility values shown on figure 10. The expression [3]

$R_{\perp} / R_{\|} \sim \frac{\mu_{1}^{2}}{\mu_{1} \mu_{2}-v_{1}^{2}}$

where $\mu_{\mathrm{i}}$ are the electron mobilities and $v_{1}$, is the hole mobility, shows that at low temperature $(<100 \mathrm{~K})$ the electron mobility may dominate and $R_{\perp}$ becomes more effective than $R_{\|}$, while at high temperature the contrary is true. Moreover, for bismuth films involving thermal treatment after or during deposition (process 2 and 3 ), the hole mobility $\left(R_{\mathrm{H}}\right.$ positive) dominates, and the whole curve $\left(R_{\mathrm{H}}-T\right)$ appears as being shifted towards lower temperature values. This effect can well be interpreted as being caused by an increase in the value of $\beta$ after thermal treatment. As a consequence the thermal treatments (processes 2 and 3 ) that have already been shown to have an impact on both the grain size and the mean free path value also appear to increase the texture of the film.

The results of the electrical measurements under strain will hereafter be discussed in terms of a physical mechanism related to the electric transport properties of the films.

The band structure of a bulk semimetal has the form shown in figure 14 with a small overlap between the valence band and the conduction band which has been estimated to be $\Delta=37 \mathrm{meV}$ [24].

According to R. W. Keyes [25] the dependence of $\Delta$ on the strain tensor is given by :

$\Delta^{\mathrm{C}}=\Delta+E_{1}\left(\varepsilon_{1}+\varepsilon_{2}\right)+E_{2} E_{3}$ where $\Delta^{\mathrm{C}}$ represents the overlap of the band minima under strain, $\varepsilon_{1}, \varepsilon_{2}$ and $\varepsilon_{3}$ the strain values along axes 1,2 and 3 ( 1 the binary axis, 3 the trigonal axis and 2 the perpendicular to 1 and 3), $E_{1}$ and $E_{2}$ the deformation potentials $\left(E_{1}=-E_{2}=2.8 \mathrm{eV}\right)$ [26].

Le Contellec et al. [8] showed that in the case of oriented thin bismuth films, equation (8) can be approximated by :

$\Delta^{\mathrm{C}}=\Delta+E_{1}\left(\varepsilon_{\mathrm{L}}+\varepsilon_{\mathrm{T}}-\varepsilon_{\mathrm{Z}}\right) \simeq \Delta+E_{1} \varepsilon_{\mathrm{L}}$.

The conductivity expression given in [9] can be transformed after neglecting the terms of second order on $d_{\mathrm{g}} / l_{0}$ into [4] :

$\sigma_{\mathrm{g}}=\frac{3}{4} \frac{1-R}{R} \cdot \frac{\sigma_{0}}{l_{0}} d_{\mathrm{g}}$

from which the variation of conductivity under compression appears to be given by :

$\frac{\delta \sigma_{\mathrm{g}}}{\sigma_{\mathrm{g}}}=\frac{\delta\left(\sigma_{0} \mid l_{0}\right)}{\sigma_{0} \mid l_{0}}+\frac{\delta d_{\mathrm{g}}}{d_{\mathrm{g}}}$

The first term on the right represents $\delta n / n$ and in the case of a model consisting of two parabolic band this term is given by [8] :

$\frac{\delta n}{n \varepsilon_{\mathrm{L}}}=\frac{E_{1}}{k \theta} \times \frac{1}{\frac{F_{1 / 2}\left(\eta_{\mathrm{F}}^{\mathrm{e}}\right)}{F_{1 / 2}^{\prime}\left(\eta_{\mathrm{F}}^{\mathrm{e}}\right)}+\frac{F_{1 / 2}\left(\eta_{\mathrm{F}}^{\mathrm{h}}\right)}{F_{1 / 2}^{\prime}\left(\eta_{\mathrm{F}}^{\mathrm{h}}\right)}}$

where $\eta_{\mathrm{F}}^{\mathrm{e}}=\frac{E_{\mathrm{F}}-E_{\mathrm{c}}}{k \theta}, \eta_{\mathrm{F}}^{\mathrm{h}}=\frac{E_{\mathrm{v}}-E_{\mathrm{F}}}{k \theta}$.

$F_{1 / 2}(x)$ is the Fermi-Dirac integral of one half order and $F_{1 / 2}^{\prime}$ its derivative. $E_{v}$ is defined in figure 14 . $k$ is Boltzmann constant and $\theta$ the temperature.

The value of expression (12) has so far $[8,26]$ been evaluated only with the assumption of complete degeneracy, thus not allowing the temperature dependence of $(\delta n / n)$ to be evaluated.

According to Joyce et al. [27] the Fermi energy $\eta_{\mathrm{F}} k T$ measured from the edge of the conduction energy band, with an effective density of states equal to $N_{0}$, is related to the carrier density $n\left(n=N_{0} \frac{F_{1 / 2}}{g_{1}}\right)$ by : $g_{1} \exp \eta_{\mathrm{F}}=F_{1 / 2} \exp \left(b F_{1 / 2}\right)$

if

$-\infty<\eta_{F} \leqslant 2.1$ and $0<\frac{F_{1 / 2}}{g_{1}}<2.97$.

In the case of parabolic bands the values of $g_{1}$ and $b$ are :

$g_{1}=\frac{1}{2 \sqrt{\pi}}$ and $b=\frac{1}{\sqrt{2 \pi}}$ 
expression (12) then becomes

$$
\frac{\delta n}{n}=\frac{\delta \Delta / k \theta}{2+\frac{1}{\sqrt{2 \pi}}\left[F_{1 / 2}\left(\eta_{\mathrm{F}}^{\mathrm{e}}\right)+F_{1 / 2}\left(\eta_{\mathrm{F}}^{\mathrm{h}}\right)\right]}
$$

where $\delta \Delta=E_{1} \varepsilon_{\mathrm{L}}$.

Figures 11 and 12 show a plot of $\delta n / n$, evaluated in accordance with (14) for $F=200 \mathrm{~g}$ versus temperature. A comparison with the measured values of $|\delta \sigma / \sigma|$ or $\Delta R / R$ for films deposited according to the three different processing conditions is also shown in figures 11 and 12 .

A comparison between the theoretical estimation of $\delta n / n$ and the experimental values of $|\delta \sigma / \sigma|$ shows that the theory leading to expression (14) estimates the right order of magnitude of $|\delta \sigma / \sigma|$. It also appears for all the samples we have measured, that the conductivity after deformation is greater for the transversal than for the longitudinal ones i.e.

$\left|\frac{\delta \sigma}{\sigma}\right|_{\mathrm{T}}>\left|\frac{\delta \sigma}{\sigma}\right|_{\mathrm{L}}$.
This property is also consistent, at least qualitatively, with the model proposed by Mayadas [9]. Indeed, the sign of the first term on the right in (11), which represents $\delta n / n$, is always positive. If the effective grain size that controls the electric transport in one direction is assumed to be the average grain size along this particular direction the second term should be taken to be positive for the transversal effect, but negative for the longitudinal one.

Acknowledgments. - The authors are most grateful to G. Vialaret and P. Ribes for assisting in measurements and they also thank Richard Pekly industry with whom the present research activity is being continued. We are thankful to Dr. Berty and his group at Laboratoire de physique structurale de l'Université Paul-Sabatier de Toulouse for their contribution with electronic diffraction, to Dr. Couderc who assisted with the X-ray diffraction investigation and Dr. Roizes and Mr. Chourreau for making the Hall and conductance measurements.

\section{References}

[1] Hoffman, R. A. and Frankl, D. R., Phys. Rev. B 3 (1971) 1825.

[2] Duggal, V. P. and Rup, R., J. Appl. Phys. 40 (1969) 492.

[3] Le Traon, J. Y. et Combet, H. A., J. Physique 30 (1969) 419.

[4] Le Traon, J. Y., Thèse d'Etat, Rouen (1971).

[5] Garcia, N., Kao, Y. H. and Strongin, M., Phys. Rev. B 5 (1972) 2029.

[6] Inoue, M., Tamaki, Y. and Yagi, H., J. Appl. Phys. 45 (1974) 1552.

[7] Kochowski, S. and OpILski, A., Thin Solid films 48 (1978) 345.

[8] Le Contellec, M., Le Traon, J. Y. and Combet, H. A., J. Physique 32 (1971) 553.

[9] Mayadas, A. F., Shatzkes, M., Phys. Rev. B 1 (1970) 1382.

[10] AVRIL, J., Encyclopedie Vishay d'analyse des contraintes (Vishay Micromesures) 1974.

[11] Tiselius, A., Franklin, J., Inst. 228 (1939) 797.

[12] Wiedermann, E., Chimia 2 (1948) 25.

[13] Société RichARD, J., Rapport d'étude final, capteurs à couches minces (1976).

[14] ASTM, Powder Diffraction File (ASTM, Philadelphia, Pa.) 1967.
[15] Komnik, Yu. F., Palatnik, L. S., Sov. Phys. Solid State 7 (1965) 429.

[16] David, M. J., Berty, J. et Lafourcade, L., Thin Solid Films 46 (1977) 177.

[17] Thureau, P., Lemiere, B. et Colombani, A., C. R. Hebd. Séan. Acad. Sci. 250 (1960) 3946.

[18] Colombani, A., Laniepce, B. et Huet, P., C. R. Hebd. Séan. Acad. Sci. 251 (1960) 1618.

[19] Kuwahara, K. and Nishimura, A., Thin Solid Films 15 (1973) 149.

[20] Neuman, M. R. and Ko, W. H., J. Appl. Phys. 37 (1966) 3327.

[21] Neuman, M. R., Thesis, Case Inst. of tech. Cleveland, Ohio (1966).

[22] Abeles, B. and Meiboom, S., Phys. Rev. 101 (1956) 544.

[23] Salardenne, J., Thèse d'Etat, Bordeaux (1965).

[24] KaO, Y. H., Phys. Rev. 129 (1963) 1122.

[25] Keyes, R. W., Phys. Rev. 104 (1956) 665.

[26] Jain, A. L., JaGgi, R., Phys. Rev. 135 (1964) 3A, A 708.

[27] Joyce, W. B. and Dixon, R. W., Appl. Phys. Lett. 31 (1977) 354. 